\title{
'Is Ash Falling?', an online ashfall reporting tool in support of improved ashfall warnings and investigations of ashfall processes
}

\author{
Kristi Wallace $^{1 *}$, Seth Snedigar ${ }^{2}$ and Cheryl Cameron ${ }^{2}$
}

\begin{abstract}
The primary volcano hazard in Alaska is airborne ash, which endangers aircraft flying the busy North Pacific air routes and consequently affects global commerce. Downwind ashfall is also a significant threat to commerce, transportation and day-to-day activities in nearby Alaska communities. A web-enabled database, "Is Ash Falling?" has been developed to collect ashfall observations and encourage sample collections from the public during eruptions, enabling volcano observatory staff to concentrate on eruption response. Knowing the locations of filed ashfall reports improves public ashfall warnings and forecasts by providing on-the-ground checks for ash dispersion and fallout computer models and satellite imagery interpretation. Reports of ashfall are shared with emergency management agencies and the wider public. These reports also give scientists a more complete record of the amount, duration and other conditions of ashfall.
\end{abstract}

Keywords: Ashfall; Web tools; Citizen science; Ash collection; Ash observations

\section{Background}

As a result of its fine-grained abrasive character and widespread distribution by wind, volcanic ash is a major hazard to aviation while ash fallout to the ground can pose significant hazards to flora, fauna, and infrastructure (Casadevall 1994). Monitoring volcanic ash dispersion in the atmosphere is typically done by observing ash clouds in satellite imagery or relying on pilot and other observer reports. The use of satellite images of drifting ash clouds as a measure of hazard assessment is a widespread practice in aviation. Nine Volcanic Ash Advisory Centers (VAAC's), established across the globe, aid flight safety by providing reports and forecasts for the movement of volcanic ash plumes (Mastin et al. 2009). Monitoring ash fallout at or near the ground is, however, less common practice and typically ad hoc. Ash fallout may be monitored by ground-based particulate monitors, observers, and in some cases, satellite imagery. Particulate monitors that are in place to measure other contaminants such as local industrial pollution could also monitor volcanic ash fallout. These instruments are typically operated

\footnotetext{
* Correspondence: kwallace@usgs.gov

'U.S. Geological Survey, Alaska Volcano Observatory, Anchorage, Alaska, USA Full list of author information is available at the end of the article
}

by regulatory agencies (e.g. United States Environmental Protection Agency) and are usually utilized in populated areas or areas of known air quality problems; these factors limit their geographic coverage for ash fallout monitoring and sample collection. Some satellite data (e.g. MODIS, Moderate-resolution Imaging Spectroradiometer) can detect some ash deposition when the contrast between the ash deposit and the ground surface is high (e.g. fallout on snow, ice, or grasslands), although these images give little information about the nature and amount of ashfall. Observer reports of ash fallout are among the best sources of information because they can include details about the timing, amount, and nature of ash fallout over vast geographic areas. Observers also often can provide physical samples of the ash deposit.

Timely observations of ashfall are used to inform public ashfall warnings and aid the understanding of ash fallout processes (Wallace et al. 2013). Recent developments in ash fallout modelling are dependent on good groundtruth data in order to simulate realistic ash fallout maps (Schwaiger et al. 2012). High-quality observer and other ground-based monitoring data can be used to inform fallout model development, interpret satellite imagery, and provide time-sensitive information on the nature of 
ashfall as well as provide research-quality physical samples (Adleman et al. 2010).

For decades, the Alaska Volcano Observatory (AVO) has requested the public's assistance in making observations and collecting ashfall samples during eruptions to help inform government-issued formal hazard advisory products and understand the ensuing eruption and its products. AVO receives the vast majority of ashfall reports from the public even though there are other agencies with mandates to provide formal warnings of ashfall and impacts from ashfall. Over the past 20 years, AVO has requested and received ash samples and information about ashfall from the public by telephone, email, web, mail campaigns, and civic speaking forums, typically with one or more staff members personally interacting with each reporting individual. AVO also specifically seeks observers from the NWS Cooperative Observer Program (Weather Spotters, http://www.nws.noaa.gov/om/coop/, last accessed 19 September 2014) and the State of Alaska Division of Community and Regional Affairs Community Database Online (http://commerce.alaska.gov/cra/DCRA External/, last accessed 19 September 2014). However, these methods for collecting observations and requesting samples are not always practical or efficient during an active eruption, when Observatory staff are busy responding or when an eruption impacts large population centers. For example, during the 2009 eruption of Redoubt Volcano, there were 19 explosive events that produced ash fallout (Wallace et al., 2013). Due to the geographically large impact area and high population density in the area of ashfall, AVO was inundated with a large volume of phone calls and emails regarding ash fallout and struggled to efficiently manage the citizen ashfall reports.

In response to the Redoubt situation, AVO developed a database module and web interface to more efficiently collect and manage ashfall observations made by both the public and scientists. The database has the ability (1) for large numbers of people across wide geographic areas to report ashfall without direct supervision from Observatory staff, (2) to collate multiple reports into a single document for quick viewing and analysis, (3) to visualize reports on a map base for internal and public viewing, and (4) for partner agencies to view reports without direct communication with Observatory staff.

\section{Database design and web interface}

A database storage schema serves as the backend to our ashfall reporting relational database. The schema is composed of one primary table, with four associated lookup tables that request basic information (state names, country names, datum names, and AVO personnel names). Fields are described in Table 1 . These database tables and related data are stored in a MySQL database management system. PHP programming language is used to insert, update and retrieve data from the database. The database module is fully integrated within GeoDIVA, the database underlying AVO's public and operational web sites. We use Google Maps API web service to display dynamic spatial data.

When a user submits a new ash report to the system through the web interface, the report is automatically added to the database. Users can click on a map to mark their location which is automatically geocoded. If the user enters a physical (street) address, the address is sent to a Google geocoding service, which returns latitude and longitude, and an accuracy value describing how close the value is to the actual location given. If the geocoding service is unable to determine a location, the address is flagged. This prevents the address from being sent to Google multiple times. AVO staff make an attempt to manually geocode unknown locations, but knowing the city and state of ashfall is also useful information and such reports are used in hazard analysis. If the user has entered an email address, an automated confirmation email is sent to them, thanking them for their contribution. Also on report submission, an email and a text message are sent to specific AVO personnel, so they do not have to monitor the database continuously for incoming reports. All ash reports are available to AVO personnel in map, .csv, and .html file formats.

The AVO website hosts web forms for the public to enter ashfall data (http://www.avo.alaska.edu/ashfall/ ashreport.php). Reports of ashfall can be entered either in near real time or retrospectively following an eruptive event. During an eruption, AVO's public website displays a map version of submitted ash reports. The publically-viewable ashfall map updates every five minutes to help reduce the load of queries to our database server. Internally, the dynamic map and related table views are updated on each new page-load, so Observatory staff always see the most current information. The public map does not display personal information and truncates ashfall report locations to two decimal places, protecting the location privacy of users submitting reports.

\section{The observer's experience}

During an eruption, AVO's website directs visitors to eruption-specific pages of information, and requests ashfall reports. AVO's ideal ash report contains a lot of specific data, entered in specific fields and formats. To assist with user-completion and data integrity, we created input forms that reduce error and hopefully encourage more robust reports. The user is presented with a series of four web forms that answer four main questions: when was the observation? (Figure 1); where was the observation? (Figure 2); what was the duration and amount of ash fallout? (Figure 3); what is the user's contact information? (Figure 4). 
Table 1 The main database table and its essential fields

\begin{tabular}{lll}
\hline Field name & Description & Comments \\
\hline Id & Primary key for ash reports; autonumber & \\
Address & $\begin{array}{l}\text { Free-text field for user to report the street address where many reports may come from areas of Alaska } \\
\text { ashfall report is being made }\end{array}$ & $\begin{array}{l}\text { without a designated street address, this field (or any other } \\
\text { location-descriptive field) may be null and is not constrained } \\
\text { to a database of street addresses - whatever someone uses } \\
\text { to describe their location, we'd like to see it. }\end{array}$
\end{tabular}

City

State_ID

Country_ID

Zip

Datum

Ash_present

Ash_sampled

Ashfall_date

Ashfall_time

Ashfall_timezone

Ashfall_start

Ashfall_end

Event_datetime

Location

Duration

Measurement_comments

Weather_types

Weather_comments

Comments

Ash_confirm

Ash_measured

Ash_amount

Ash_thick
Free-text field for user to report the city where the ashfall report is being made

Foreign key to another table listing US states

Foreign key to another table listing countries - presents as a drop-down to users

Free-text field for zip code

Foreign key to another table listing datums

Presents as a checkbox to the user; stored in the table as 'yes' and 'no' entries

Presents as a checkbox to the user; store in the table as 'yes' and 'no' entries

Date of ashfall observation: yyyy-mm-dd; user can pick from a calendar

Time of ashfall observation: hh:mm:ss

Free-text field for user to input the timezone for date/ time of ashfall observation

Free-text field for user to describe when ash started falling

Free-text field for user to describe when ashfall ended

Free-text field for AVO staff to associate user's ashfall report with the time of a specific explosive event

Free-text field for user to describe the location of the ashfall report

Free-text field for the user to report the duration of the ashfall

Free-text field for the user to make comments on the quality of their ashfall measurement

Restricted text of 'windy', 'snowy', 'rainy', and 'calm' presented to the user as multiple checkboxes. Users may select more than one option

Free-text field for user to describe the weather during the time of ashfall

Free-text field for user to report any additional information on ashfall to AVO

True/False field for AVO to enter whether or not the ashfall report is verified

Yes/No field for user to enter whether or not they measured the ash; presents to the user as a checkbox

Restricted text to 'trace', 'minor', 'substantial', or 'heavy'; presents to the user as as choose-only-one drop-down

Field for AVO staff to enter how thick the ash for this report actually is/was, in $\mathrm{mm}$
Other parts of our database already linked to a table listing states

Other parts of our database already linked to a table listing countries

Areas of the United States with smaller and more welldefined zip code areas may wish to link to a restricted list of valid zip codes

Other parts of our database already linked to a table listing datums 
Table 1 The main database table and its essential fields (Continued)

\begin{tabular}{|c|c|c|}
\hline Aggregates & $\begin{array}{l}\text { True/False field for AVO staff to enter whether or not the } \\
\text { ash contained aggregates }\end{array}$ & \\
\hline Grain_size & $\begin{array}{l}\text { Restricted text to 'fine', 'medium', 'coarse', and 'very } \\
\text { coarse' - data entered by AVO staff }\end{array}$ & \\
\hline Color & $\begin{array}{l}\text { Free-text field for AVO staff to describe the color of the } \\
\text { ash }\end{array}$ & \\
\hline Sulfur_smell & $\begin{array}{l}\text { True/False for AVO staff to code the report if the user } \\
\text { mentions a sulfur smell }\end{array}$ & \\
\hline Sample_type & $\begin{array}{l}\text { Restricted text to 'none', 'MPUA', 'bulk', 'time_series', or } \\
\text { 'multiple' for the user to describe their ash sample }\end{array}$ & We provide definition links next to these terms in the form \\
\hline Pers_name & Name of the person submitting the report & All personal identifying information is optional \\
\hline Pers_email & Email address of the person submitting the report & \\
\hline Pers_phone & Phone number of the person submitting the report & \\
\hline Oktocontact & $\begin{array}{l}\text { Yes/No for whether AVO may contact the user } \\
\text { submitting the report; "Can we call you for more } \\
\text { information?" }\end{array}$ & \\
\hline Avo_contact & Foreign key to list of AVO personnel & $\begin{array}{l}\text { Used to keep track of which AVO staff are communicating } \\
\text { with specific observers }\end{array}$ \\
\hline Communication & $\begin{array}{l}\text { Free-text field for AVO staff to make notes about } \\
\text { communications with an observer }\end{array}$ & \\
\hline Thank_you_sent & $\begin{array}{l}\text { Yes/No field for AVO staff to mark whether a personal } \\
\text { thank you (phone call, real email message) has been } \\
\text { sent }\end{array}$ & \\
\hline Ex_event_seismic & $\begin{array}{l}\text { Free-text field for AVO staff to code the report to a } \\
\text { specific seismic event }\end{array}$ & \\
\hline Ex_event_UTC & $\begin{array}{l}\text { Free-text field for AVO staff to code the report a specific } \\
\text { explosive event's UTC time }\end{array}$ & \\
\hline Volcano_id & $\begin{array}{l}\text { Foreign key to AVO's list of Alaska volcanoes, for AVO } \\
\text { staff to link an ash report to a specific volcano. }\end{array}$ & \\
\hline Submitted & Date/time stamp of when the ash report was submitted & \\
\hline Utc_offset & Offset of users' computer to UTC & $\begin{array}{l}\text { User likely inputs times based on their local time; this fields is } \\
\text { autopopulated with UTC time, based on the user's time zone }\end{array}$ \\
\hline Google_map_loc & Point of click on google map & Selected by user \\
\hline Google_latitude & Geocoded latitude & \\
\hline Google_longitude & Geocoded longitude & \\
\hline Google_accuracy & Accuracy level of geocoding & \\
\hline Google_failed & $\begin{array}{l}\text { True/False; coding returns "true" if google failed to } \\
\text { geocode the record }\end{array}$ & \\
\hline
\end{tabular}

- Web-form 1 (Figure 1): Timing of the observation. The date and time are automatically filled with the current date and time; if a user clicks within the window to edit it, a calendar pops up.

- Web-form 2 (Figure 2): Location of the observation. Because many areas of Alaska are remote and not within a populated area or zip code, users have several options for reporting location. If a user clicks a location on the map and also enters a physical address, the map location is used. Location information is not required to submit a report.

- Web-form 3 (Figure 3): Duration and amount of ash fallout. This form initially presents the instruction
"If ash was present, click this checkbox". If users do not click the checkbox, they immediately advance to the final entry form. Reports of no ashfall are also valuable because they are used to update public hazard notifications and help calibrate model outputs. If the users do check the box, they are prompted for further details about the ashfall. If they check that they measured the ash, the window expands for ash thickness information. If they further check that they collected a sample, the window expands to the extent shown in this figure. Although we would like users to enter their start and stop times with precise military time, the form is a free-text field to encourage users to report the 


\section{IS ASH FALLING?}

\section{ARE YOU EXPERIENCING ASHFALL? We are interested in both YES and NO answers!}

Reports of ash fall are important to us; we use your observations to assess the character and size of an eruption plume. We report these data to the National Weather Service so they can keep their Ashfall Advisories current. Additionally, reports of NO ashfall during an eruption with expected ashfall are also important to us. Thank you for your participation in volcano science!

Ash collection instructions

\section{When did you make this observation?}

yyyy-mm-dd: 2014-04-16

24hr hh:mm: 15:59:00

Time zone:

Step 1 of $4:$ : Continue $>>$

Figure 1 Web-entry screen 1 of 4 which requests information about the timing of the observation.

timing as best they can. The predefined choices for ashfall thickness are used in formal hazard statements in the US and are easier for users to quantify and select.

- Web-form 4 (Figure 4): Contact information. This form emphasizes that AVO will not distribute personally identifiable information (PII), and specifically states how AVO will use their information. The ash report is not submitted to AVO unless the submitter checks the "Send ash report" button. After sending, AVO confirms the ash submission on screen, and sends an automated "thank you" email if the user provided an email address and permission for contact.

AVO provides ashfall collection instructions in many locations on the webpage, in a variety of formats, including printable instructions, a datasheet, illustrated web pages, and a video tutorial (Wallace and Kristi 2009).

During an eruption, reports submitted via the web form automatically generate a public ashfall report map (Figure 5) displayed on the activity page of the erupting volcano on AVO's webpage. The map shows the location of both positive (+, yes ash) and negative (-, no ash) reports of ashfall over a 24-hour period. Symbols are color-shaded by time in order to discriminate multiple ashfall events. Reports that are not successfully geocoded are not included on the map display but still exist as reports and show up in the list and spreadsheet views which are available only to Observatory staff. The public map is updated every five minutes, without personally identifiable information and with reduced-precision locations. The public map also bears a disclaimer that the map may contain erroneous reports. AVO attempts to correct errors when we find them, time permitting. There are no minimum submission requirements, although incomplete reports are of limited value and those without both location and notation (by checking boxes) whether ash is present or not, will not be displayed on the map. This map is the only automatic display of ashfall information available to the public; other information known about ashfall is delivered as formal ashfall warning messages (refer to the following section on "how the ashfall reporting database is used in eruption response"). We chose to display only information on the occurrence $(+)$ or lack of $(-)$

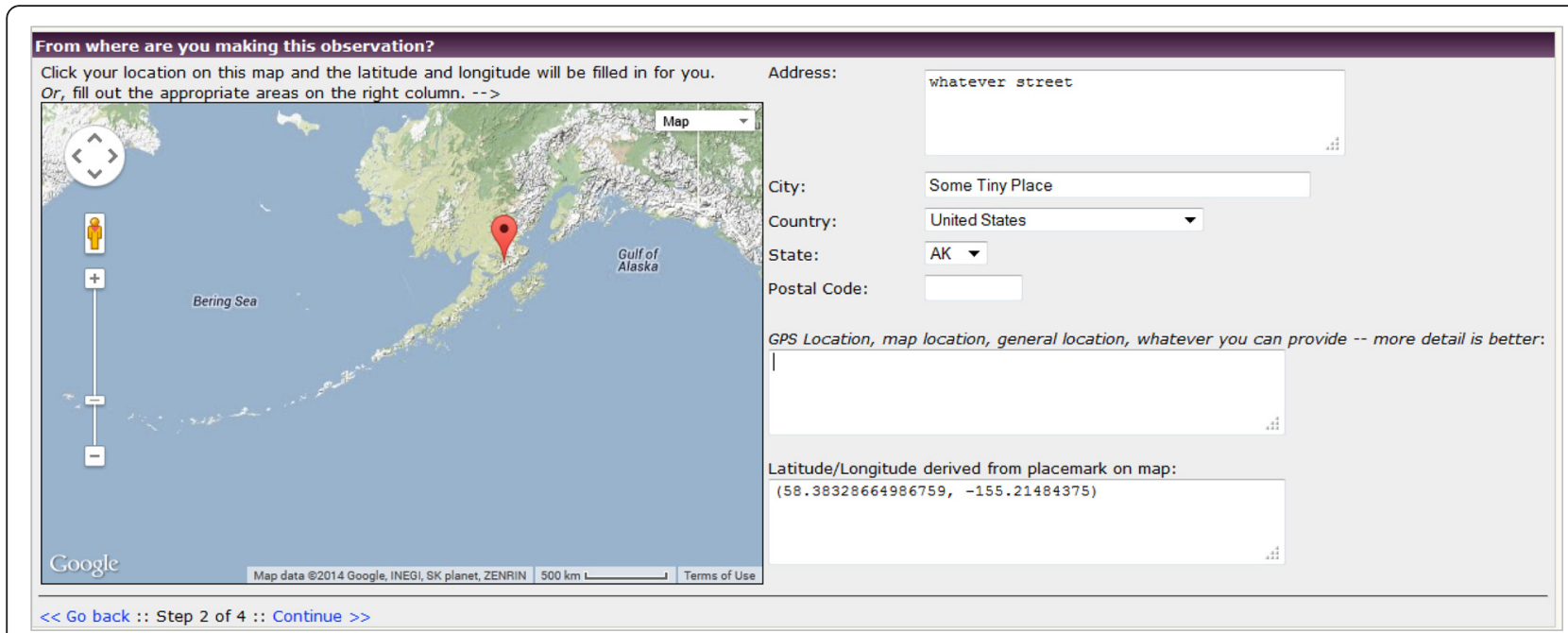

Figure 2 Web-entry screen 2 of 4 which focuses on the ash report's location. 
Was ash present in this observation?

If ash was present, click this checkbox $->\nabla$

Please report in local time, using 24-hr (military time) numbers, hh:mm:ss

When did the ash start falling? 7 am

When did the ash stop falling? hasn't yet stopped

If you measured the thickness of the ash layer, click this checkbox $->\nabla$

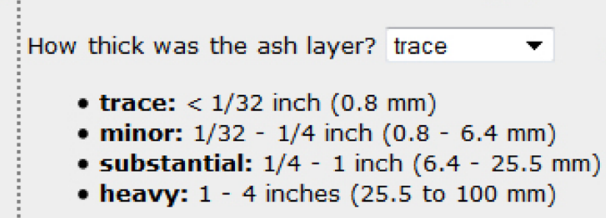

What was the weather like? Any comments on the weather?

$\square$ Windy
$\square$ Snowy
$\square$ Rainy
$\square$ Calm

If you took a sample of the ash, click this checkbox $->\nabla$

- MPUA: Measured area sample (more info ...)

Any comments on your measurement?

- bulk: bulk sample (more info ...)

- time_series: samples collected over a period of time(more info ...)

- multiple: multiple samples collected

<< Go back :: Step 3 of 4 :: Continue >>

Figure 3 Web-entry screen 3 of 4 which focuses on duration and amount of ashfall.

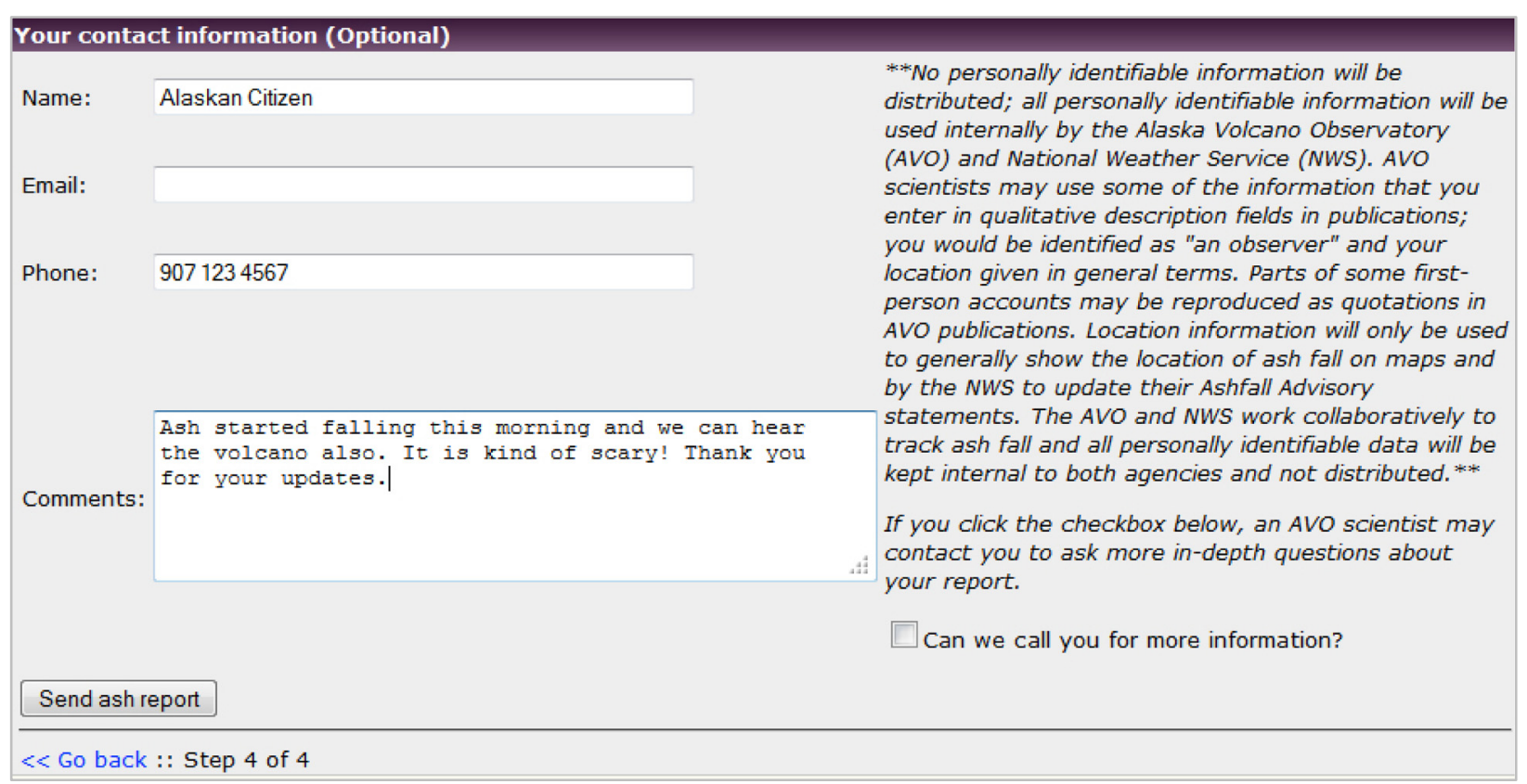

Figure 4 Web-entry screen 4 of 4 which asks for contact information and permission for contact. 


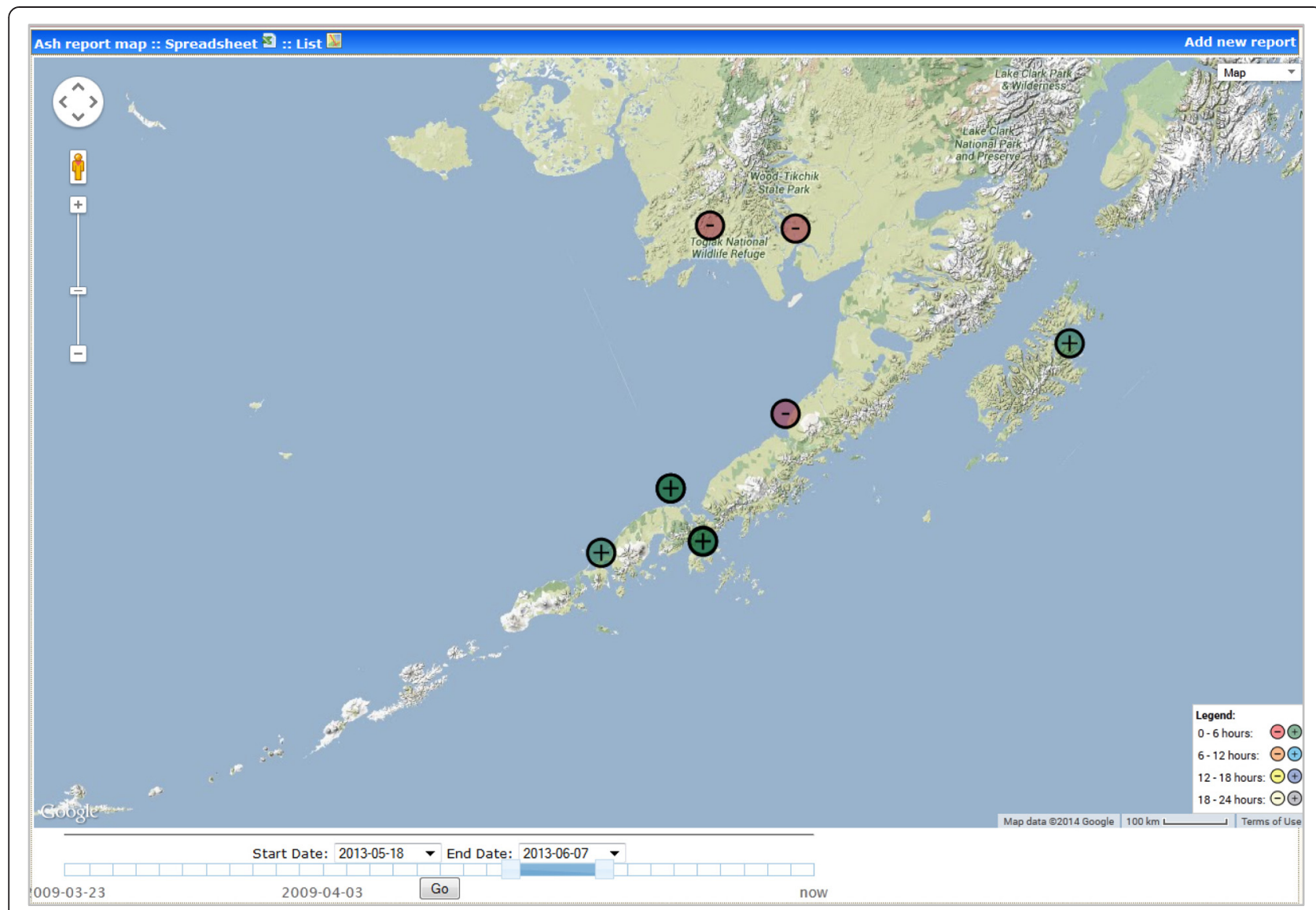

Figure 5 Screenshot of AVO's internal review map, timeline adjusted to show a snapshot during the Pavlof 2013 eruption. Ashfall reports are coded by + and - signs, and color-shaded by time.

ashfall because it is the most reliable data collected from the public. Other data on ashfall (such as thickness), are often erroneous perhaps due to confusion between metric versus English units and often require follow-up calls to verify. Extended data on ashfall collected from the public (deposit thickness, ashfall duration, weather conditions during ashfall, and timing of ashfall) are verified by AVO before forwarding the information to agency partners who may use these data in formal warning products.

The bottom of each page of the ashfall reporting forms also bears our US Office of Management and Budget (OMB) control number, the expiration date, and the Paperwork Reduction (1980), a requirement by the US Federal government when collecting data from the public via a government website.

\section{The Observatory's experience}

When a user clicks the "send ash report" button, the data are entered into our database, location information is geocoded, AVO's internal review map, .csv, and .html reports are updated, and a notification email and text message is sent to designated AVO staff members. There are no restrictions on the internal review map (Figure 5), unlike the public map, and AVO staff can click on the map icons (+ and - symbols) to obtain detailed information about ashfall observations, and can contact the observer for clarification if permission is given by the observer. An adjustable timeline (year, month, day) located at the bottom of the internal review map adjusts the view to display observations from specific ashfall events or all observations over a specified time frame.

Observatory staff may also update individual ash reports with new or different information, or delete "just for fun" or erroneous reports. Using an internal review web form, AVO staff can tab through three pages of user-submitted content and three additional pages dedicated to internal information (see Table 1). This allows AVO staff to confirm or deny ambiguous ashfall reports. Additional information that AVO staff may attach to an ashfall report include: volcano name, explosion time, sulfur smell, deposit color, grain size, whether aggregates are present, and a thickness of the deposit in millimeters. These details are not requested via the standard web form for several reasons: we wanted to keep the form brief; we want to encourage reporting of ashfall, even when these details are not known; and we can gain this information 
more reliably with follow-up calls. Our review form also lets us keep a time-stamped running communications log about each ash report.

\section{Discussion}

How the ashfall reporting database is used in eruption response

With the ashfall database, AVO staff condenses and summarize the various ashfall reports and forward information on to other agencies, emergency managers, and the wider public. The online, automatic database frees staff resources during very busy eruptive periods, especially compared to AVO's previous requests that individuals phone AVO with ashfall reports. Because most reports of ashfall come to AVO rather than other agencies, this new system provides a much more efficient means of digitally collecting, displaying, and distributing such information to other agencies and the public.

During ash-producing eruptions AVO works directly with NOAA's National Weather Service (NWS), the agency responsible for issuing public ashfall warning messages and advisories about airborne ash clouds (in Alaska). These reports from the public also give scientists a more complete record of the location, amount, duration and other conditions of ashfall that are used to improve both NWS and AVO hazard advisory products.

Previously, AVO called the NWS for each ash report, which often was redundant and time consuming. AVO now shares a version of the database with the NWS so they have the same information at the same time as the Observatory. NWS staff can see which reports have been verified by AVO and which have not, and use this information to inform their warning messages, or they can call AVO for clarification as needed. Because AVO staff manually enter those ashfall reports that still sometimes do arrive via phone and email into the database, all information known to AVO about ashfall is contained in the ash reporting database allowing for easy querying.

Reports of ashfall are also shared with other agencies responsible for various impacts from ashfall, including the Alaska Department of Environmental Conservation (AK-DEC) Division of Air Quality Program, the AK-DEC Division of Environmental Health Drinking Water Program, and the Alaska Department of Health and Social Services Public Health Division (AK-DHHS), which have a mandate to warn of possible impacts to air quality, drinking water quality and public health, respectively. (For additional information on AVO's information dissemination procedures, see Madden et al. 2014).

\section{Scientific benefits of the ashfall reporting database}

First-hand accounts of ashfall support development of ash dispersion and deposition models, interpretation of satellite imagery, and guide field mapping. Public collection of samples improves researchers' ability to perform timeincremental studies and make isomass maps of ashfall across broad geographic areas that would otherwise not be possible.

Ash fallout modelers make assumptions about eruption parameters, such as particle size distribution, particle density and mass of erupted material (Mastin et al. 2009). Ground-truth information about the timing, thickness and accumulation rate can be used to calibrate these models so that realistic model simulations can be produced (Schwaiger et al. 2012).

Satellite imagery is most often used to track drifting ash clouds overhead and, occasionally, ash fallout on the ground. Discrepancies between the amount, location and timing of overhead ash clouds and subsequent ash fallout on the ground may be explained with better groundtruth data on ashfall.

Physical samples and field measurements of typically ephemeral deposits used to calculate mass and volume of erupted material are important to more accurate estimates of the size of an eruption. Many observers are in remote, off-road areas that are inaccessible to Observatory staff during ashfall. Reports and samples of such deposits are unlikely to be known except by local observers.

AVO has now used the ashfall reporting database during several eruptive periods with ashfall: the latter stages of the Redoubt 2009 eruption, and the eruptions of both Pavlof and Veniaminof in 2013. Because Redoubt Volcano is located near Alaska's most populous region and produced 19 ash plumes during its 2009 eruption (Wallace et al. 2013), AVO received numerous ( 250) ashfall reports. "Is Ash Falling?" was not formally approved for public use until July 1 2013, so all Redoubt ash reports were manually entered into the database by AVO staff. Reports submitted via the online web forms for more recent Pavlof and Veniaminof eruptions were less numerous (19) because these volcanoes are in remote locations and populations are small, but if it were not for these observations, we would have no information about ashfall. Submission via the online form proved an efficient way to both learn about ashfall across the Observatory and to forward to other emergency managers. We also think that the web form helped to improve the quality of observations because the questions guide users through the report.

\section{Naming the ashfall reporting database}

To be consistent with other online public observation databases developed by the USGS and its cooperators such as "Did you feel it?, Earthquake reporting database (2005)" for reporting felt earthquakes, and "Did you see it?, Landslide reporting database (2014)" for reporting landslides, we named the ash reporting database, "Is Ash 
Falling?". It is the first of its kind to collect observations during an event rather than after an event has occurred. We hope that product branding from these very successful and well-known databases will facilitate the recognition and use of our ashfall reporting database even in international settings.

\section{Potential for portability of "Is Ash Falling?"}

This database was designed for the Alaska Volcano Observatory where ashfall events are common and occur on average 1-2 times per year. Users are permitted to submit reports from locations outside of Alaska which is intended to capture ash fallout originating from Alaska volcanoes from widely dispersed ash clouds. The database is, however, open-source and can easily be exported and modified for use at other observatories or agencies that collect information on ashfall in the US and internationally. This tool will soon be operational at other US volcano observatories. AVO is currently working with the Institute of Geological and Nuclear Sciences (GNS) in New Zealand to create an international version of "Is Ash Falling?" for use in New Zealand. Contact the authors for more information on obtaining the code for this database.

There is potential for designing a single "Is Ash Falling?" database that could be used to report ashfall anywhere on earth, similar to how the USGS "Did You Feel It?, Earthquake reporting database (2005)" database currently works for reporting earthquakes. Considerations about data management however, have prevented us from pursuing such a version at this time.

\section{Lessons learned in development}

Because of the more than 20 years experience requesting the public's assistance in making observations and collecting ashfall samples during eruptions, AVO had already developed successful paper-based data-collection forms. Questions from these forms were used as the framework for developing the on-line tool. AVO also already had a MySQL database underlying its public and operational web sites so the ash-reporting database was created as a module using the same programming language and table structure, and was integrated into the existing database.

Concerns about user-completion and data integrity led us to design our input forms to include suggested data formats such as yyyy-mm-dd, for time, or pull-down menus rather than free-text answers. From experience however, we also include a number of free-text fields so that users do not feel so restricted that they avoid filling in the information. The initial webforms presented as several pages requesting many small bits of information, and felt overwhelming. In an effort to streamline the user experience, the current forms only expand to request further information when initial answers (yes to ashfall, yes to measurements, yes to ash collection) warrant asking these questions. We believe this will provide both a better user experience and greater data integrity. For example, people who report negative ashfall will not also be able to report an ash thickness.

We also realized that because AVO cannot instantly verify all reports, if we wanted to display + and - ashfall reports on the public website, we needed a disclaimer on the public map. We also developed faster ways for Observatory staff to delete erroneous reports from the database.

Because we collect user identity and location information, we need to be sensitive and protect citizen's privacy. In consultation with the US Office of Management and Budget (OMB - the US government agency responsible for regulating permission to collect personally identifiable information-PII), we modified the map scale tool on the public map to restrict the location precision, protecting PII. Precise ashfall locations are not needed for formal NWS Ashfall Advisory statements, but are of great assistance to ashfall modelers and Observatory scientists. Potentially the most timeconsuming part of developing "Is Ash Falling?" was applying for and obtaining the permissions required by the US Federal government for collecting data from the public via a government website. This process took 1.5 years to complete and was a required step in making the database operational.

As both AVO and the public gain experience in using "Is Ash Falling?", we would like to survey Observatory staff and the public at some future point in time for their suggestions on improvements and modifications.

\section{Conclusions}

"Is Ash Falling?", AVO's online, public, ashfall reporting system provides a much more efficient means of collecting, displaying, and distributing information about ashfall during eruptions for wider use by other agencies, emergency managers, and the public. First-hand accounts of ashfall gathered by the on-line system can provide time-sensitive information about the location, amount, duration and other conditions of ashfall that are used to improve our interpretation of satellite imagery, provide public warnings, improve ashfall model development, and guide field mapping. The online, automatic database frees staff resources during very busy eruptive periods while providing a stream of critical hazard information to the Observatory. Samples of ash fallout collected by the public can provide research-quality physical samples across broad geographic areas that would otherwise not be available for analysis. 


\section{Abbreviations}

API: Application Programing Interface; AVO: Alaska Volcano Observatory; AK-DEC: Alaska Department of Environmental Conservation; AK-DGGS: Alaska Division of Geological \& Geophysical Surveys; AK-DHSS: Alaska Department of Health and Social Services; GNS: Geological and Nuclear Sciences; GeoDIVA: Geologic Database of Information on Volcanoes in Alaska; MODIS: Moderate-resolution Imaging Spectroradiometer; NWS: National Weather Service; OMB: US Office of Management and Budget; PHP: hypertext Preprocessor scripting language; PII: Personally Identifiable Information; US: United States of America; VAAC: Volcanic Ash Advisory Center.

\section{Competing interests}

The authors declare that they have no competing interests.

\section{Authors' contributions}

KW is a U.S. Geological Survey geologist with the Alaska Volcano Observatory whose research focus is volcanic ash. Her responsibilities during eruptions include mapping and collecting volcanic ash to characterize and calculate mass and volume of erupted products. She also coordinates ashfall information with emergency managers during ashfall events in Alaska. SS is the computer systems and database manager for the AVO website at the Alaska Division of Geological \& Geophysical Surveys (AK-DGGS). CC designs and populates the Geologic Database of Information on Volcanoes in Alaska (GeoDIVA). All authors read and approved the final manuscript.

\section{Authors' information}

KW is a U.S. Geological Survey geologist with the Alaska Volcano Observatory whose research focus is volcanic ash. Her responsibilities during eruptions include mapping and collecting volcanic ash to characterize and calculate mass and volume of erupted products. She also coordinates ashfall information with emergency managers during ashfall events in Alaska. SS is the computer systems and database manager for the AVO website at the Alaska Division of Geological \& Geophysical Surveys (AK-DGGS). CC designs and populates the Geologic Database of Information on Volcanoes in Alaska (GeoDIVA)

\section{Acknowledgements}

We would like to thank Angie Diefenbach for collating ash reports during the 2009 eruption of Redoubt volcano used as the basis in developing "Is Ash Falling?".

\section{Author details}

'U.S. Geological Survey, Alaska Volcano Observatory, Anchorage, Alaska, USA. ${ }^{2}$ Alaska Division of Geological \& Geophysical Surveys, Alaska Volcano Observatory, Fairbanks, Alaska, USA.

Received: 29 May 2014 Accepted: 26 December 2014

Published online: 24 February 2015

\section{References}

Adleman JN, Cameron CE, Snedigar SF, Neal CA, Wallace KL (2010) Public outreach and communications of the Alaska Volcano Observatory during the 2005-2006 eruption of Augustine volcano. In: Power JA, Coombs ML, Freymueller JT (eds) The 2006 eruption of Augustine Volcano. Geological Survey Professional Paper 1769, Alaska: U.S, pp 631-644 [http://pubs.usgs. gov/pp/1769/chapters/p1769_chapter27.pdf]

Casadevall TJ (1994) Volcanic ash and aviation safety: proceedings of the first international symposium, Seattle, Washington, July 1991. In: U.S. Geological Survey Bulletin B 2047., p 450

Did you feel it?, Earthquake reporting database (2005) U.S. Geological Survey, Denver, CO. http://earthquake.usgs.gov/earthquakes/dyfi/. Accessed 19 September 2014

Did you see it?, Landslide reporting database (2014) USGS Denver, CO. [http://landslides.usgs.gov/dysi/]. Accessed 19 September 2014.

Madden J, Power J, VanPeursem KW, Holt G, Devaris A, Brennell J, Hartig L (2014) Alaska interagency operating plan for volcanic ash episodes., p 51, http://www.avo.alaska.edu/pdfs/cit3996_2014.pdf

Mastin LG, Guffanti M, Ewert JE, Spiegel J (2009) Preliminary spreadsheet of eruption source parameters for volcanoes of the world: U.S. Geological Survey Open-File Report 2009-1133, v. 1.2., p 25 [http://pubs.usgs.gov/of/ 2009/1133/]
Paperwork Reduction Act (1980) Pub. L. No. 96-511, 94 Stat. 2812, codified at 44 U.S.C. § 3501-3521

Schwaiger HF, Denlinger RP, Mastin LG (2012) Ash3d, a finite-volume, conservative numerical model for ash transport and tephra deposition. Journal of Geophysical Research 117:B04204, doi:10.1029/2011JB008968

Wallace, Kristi L. (2009) Alaska Volcano Observatory Ash Collection Instructions. http://www.avo.alaska.edu/ashfall.php]. Accessed 22 September 2014

Wallace K, Schaefer J, Coombs M (2013) Character, mass, distribution, and origin of tephra-fall deposits from the 2009 eruption of Redoubt Volcano, Alaska-highlighting the importance of particle aggregation. JVGR special issue: 2009 Redoubt Eruption 259:145-169 [http://dx.doi.org/10.1016/ j.jvolgeores.2012.09.015]

\section{Submit your manuscript to a SpringerOpen ${ }^{\odot}$ journal and benefit from:}

- Convenient online submission

- Rigorous peer review

- Immediate publication on acceptance

- Open access: articles freely available online

- High visibility within the field

- Retaining the copyright to your article

Submit your next manuscript at $>$ springeropen.com 